\title{
The Promise of Collaborative Management Research
}

\author{
William A. Pasmore
}

Bengt STYMne

\author{
A. B. (RAMI) SHANI
}

Susan Albers Mohrman

Niclas AdLER

A $\mathrm{s}$ editors of the Handbook of Collaborative Management Research, we began this project with a firm belief based on our experience that broader and deeper collaboration between managers of organizations and academic researchers could yield significant benefits for both parties. Managers would learn much more about how organizations function and new approaches to managing complex systems, thereby improving their individual and organizational performance. Researchers would have access to organizations to discover and test new theories and hypotheses, thereby advancing knowledge and using it to enhance undergraduate, graduate, and executive education. What we didn't realize at the time was how much we would learn about collaborative management research from each other and from our colleagues who have contributed chapters to this volume. As we began work on the editorial statement and guidelines for the book, we quickly realized that we held different ideas of what collaborative management research entailed.

As we tried to define what we meant by management and collaboration, we disagreed on some basic points. Did management include both profit and nonprofit organizations? Did it include the "management" of systems that weren't even formal organizations, such as regional economies? Did it address issues that "managers" as discrete individual actors could influence, or did 
it address "management" issues that groups of people shared some collective responsibility for, even if they didn't view themselves as managers? And what did we mean by "collaboration"? How intense, extended, and personal did the relationship need to be before it qualified as collaborative? Did the sharing of decisions about research objectives, methods, and conclusions need to be determined equally by both parties, or was it enough for organizations to simply open their doors to academics? What exactly differentiated an in-depth case study from something that we would consider legitimate collaborative management research?

We were all involved in some way with an ongoing program between universities and organizations in Sweden (the FENIX Centre) in which major corporations sent individuals to be trained as organizational researchers as they worked with faculty to undertake research projects in their own organizations. The projects were conducted within the context of a long Scandinavian tradition of boundary-spanning collaboration between management researchers and companies. The logic behind the program is that by training managers to be researchers while undertaking different forms of collaborative research projects, the gap between academia and organizations can be bridged. Certainly, the founders of the program believed that managerial researchers would choose topics of great relevance to their companies and that companies in turn would find the results of their research compelling. Recently, in a book titled Collaborative Research in Organizations: Foundations for Learning, Change, and Theoretical Development, the FENIX community captured the learning from its first five years of leading and participating in some very ambitious and innovative collaborative research endeavors (Adler, Shani, \& Styhre, 2004).

The FENIX Centre will be represented in the work of several authors in this volume, so we won't go into more detail about it at the moment. The point is simply that the program created a mindset for us about what collaborative management research is, and set implicit standards against which we initially assessed other efforts.

When we began receiving manuscripts from our contributing authors covering the theory and practice of collaborative management research, we were confronted by a much broader view of what collaborative management research currently entails. We were forced to question our narrow view and opened ourselves up to the possibility that the project would be much more informative and challenging than we first imagined. We also recalibrated our assessment of progress in the field. Despite the best efforts of many of the contributors to this volume and their managerial collaborators, the practice of collaborative management research is neither well defined nor widely practiced. We see this as natural for an emergent and promising research approach. There are intriguing possibilities for the development of future modes of collaboration as we build upon the knowledge accumulated to date. The challenge involved is to continue to develop the research approach, its epistemological foundation, its research methods, and its institutional anchoring in scientific journals and textbooks. That a study is "collaborative research" is not a justification for its claims to scientific and practical relevance if it is poorly conducted. Poorly conducted studies may further erode the trust and confidence that managers have in academics to contribute relevant and timely insights in return for the support that managers provide for research.

There are important issues here. We are of the firm belief that more collaborative research can help to improve the relevance of two fields that are the targets of much criticism. Management and its practitioners are criticized in the public debate and in scholarly writings for acting irrationally based on 
unfounded beliefs and imitation (Pfeffer $\&$ Sutton, 2006). Management science and the researchers it engages are criticized for producing knowledge of little or no relevance for management practice (Ghoshal, 2005; Hoffman, 2004). We are convinced that there are ample opportunities for improvement of this situation. Management, based on better knowledge and appreciation of the specific contexts in which it acts, could contribute to socially more useful goods and less waste of resources. Management research, based on a better appreciation of management practice and the challenges it faces, could contribute to better-grounded actions and more relevant theories.

The argument for collaborative management research, at a basic level, is that by bringing management and researchers closer together, the rate of progress in understanding and addressing issues such as innovation, growth, change, organizational effectiveness, and economic development will be faster than if either managers or researchers approach these topics separately. Managers are continuously acting out models of good management but are not always aware of where the models came from, how they were developed, whether they are robust, or whether they fit the current circumstances. Management scientists are continuously building new models while keenly observing what is going on in the world of business. If the two groups join forces they will have the components necessary for faster and more relevant knowledge creation: model building, testing out models, observing consequences, and analyses of cause and effect. Closed groups and systems do not easily change or innovate. Left on their own, managers might continue to develop local solutions to organizational issues that do not draw upon the vast shared knowledge that exists, in an uncoordinated fashion and without the benefit of the latest thinking on the topic. The result would be to reinvent the wheel, misdirect or suboptimize the application of organizational resources, and ultimately achieve slower progress. On the other hand, left to their own devices, researchers could frame questions with no practical significance, draw erroneous conclusions from data, or suggest remedies that are entirely impractical. In theory at least, bringing together managers with practical experience and urgent needs with academics who are in touch with accumulated wisdom and possess the capacity for research-driven innovation should be a win-win situation for both, as well as for society at large.

This is not a new thought. In one of the chapters in this volume (Chapter 3), Tenkasi and Hay draw upon Socrates for guidance that is extremely relevant to the conduct of collaborative research today. As several of our other authors note, efforts at collaborative management research in the early part of the 20th century produced innovations ranging from time and motion studies (Taylor, 1911) to high performance work systems (Trist \& Bamforth, 1951) to human relations at work (Roethlisberger \& Dickson, 1939). These efforts were not formulated with an explicit intention of undertaking collaborative research; they were simply natural evolutions of existing collaborative relationships that led to groundbreaking projects with benefits to both the organizations involved and the field of management more broadly. It is only now as we look back on these efforts that we can see in each how perfectly the context for collaboration was created, even though it seemed so effortless that it was given almost no attention at the time.

In the intervening decades, collaborative management research has continued, as evidenced by many of the chapters in this volume. At the same time, the academic field of management research has grown and developed, using a mix of research methodologies that are more or less collaborative. By sheer volume and influence within academic circles, 
less-collaborative research has become the dominant mode, leading to current concerns that management research and thinking have become too theoretical and of less interest to managers (Huff, 2000). It is as if a large part of the field has lost touch with its roots, its audience, or perhaps both. Several of our authors note that the criteria for success in the fields of management and management research have diverged, with short-term profitability issues dominating the minds of managers, while publishing articles in the proper journals (whether or not they deal with issues important to managers) is the primary goal for academics (e.g., Werr \& Greiner, Chapter 5; Roth, Chapter 17). As a result, it is the exception rather than the rule today that conditions optimal for conducting collaborative management research develop spontaneously. Instead, much is required on the part of both parties to justify the expenditures involved, defend against critics who hold other measures of performance to be more important, and overcome the many forces that impede or limit the dissemination of knowledge (see Pasmore, Woodman, \& Simmons, Chapter 27, and other chapters in this volume).

Management science and research have undoubtedly made contributions that have had a profound impact on management practice. Academics have been instrumental in developing accounting practices that form the skeleton upon which the rest of the economic system is constructed. Operations research has contributed to the organization of production and logistics, applied psychology to methods of marketing, and advanced mathematical modeling has been instrumental for the emergence of an integrated global financial system. However, as research in a certain area of management matures into a scientific subdiscipline, the gap between practice and research widens. The result today is that astonishingly little cross-fertilization takes place between the universes of management practice and management research. Management research has become more of a closed system that is governed by relevance criteria developed internally based on idealized images of the natural sciences. Demonstrated practical usefulness is not required for research publication, and research aiming at improving the effectiveness of a particular organization may even be frowned upon by those who believe research should remain detached from those who are studied. In some of the contributions here, such as those of Roth (Chapter 17) and Knights, Alferoff, Starkey, and Tiratsoo (Chapter 19), the debate has been raised to an institutional level as universities struggle with the tensions raised by the acceptance of corporate-funded research that threatens to hijack research agendas. Incidentally, the natural sciences struggle with the same issues concerning corporate funding, but the point is still the same: Any type of relationship between those studied and the researchers involved raises the question of whether scientists can remain completely objective.

The value of objective research to the management science community is obvious. The goal of management science is to explain how managed systems function, which requires sorting out popular myths or cultural beliefs from actual underlying causes of events or outcomes. The value of objective research to managers might not be as clear initially but is just as important in the end. Management practice has always been based on past experience, trial and error, and what is "acceptable practice" inside an organization or system. Management is often based on idealized images of leadership, imitations of others, and the adoption of management fads. If "accepted practice" is in fact based on incorrect assumptions or beliefs, this can create inefficiency, malfunctioning, or even the demise of organizations over time. The result is waste in the larger economic system 
and unnecessary human suffering in social systems. Management action anchored in more careful and realistic appreciation of the situation and context of the managed system can bring more success at less cost. Management research that fulfills the criterion of practical relevance will have greater possibilities to make a difference for practice, that is, will in fact contribute to better management and higher goal fulfillment of organizations and other managed social and economic systems.

We are convinced that collaborative research spanning management science and management practice can be beneficial to both parties. Management action can be guided by tested models, systematic evaluation of present practices, and analyses of relevant information. Management research can discover, develop, and validate better models based on careful observation of the consequences of management actions. Together, practicing managers and management researchers can engage in joint reflection that clarifies the actual situation, the prior experience that might be applicable, the indicators and dimensions that would be relevant and useful to apply when evaluating progress, and the broader knowledge that could be applied to achieve greater success. Preliminary studies and experiments could be designed and carried out to obtain more information on key uncertainties before decisions are made, resources committed, and final approaches launched. Information about the consequences of actions can be gathered and interpreted through joint efforts and give inspiration for new management strategies and scientific explanations.

To advance our understanding of management, we need to conduct research that is more insightful, influential, and immediately applicable. For this, in turn, we need greater collaboration between management and researchers, which is not always easy to achieve. The promise of collaborative management research is that it will produce more powerful and applicable solutions to some of our most pressing organizational and societal issues. Whether or not we are capable of undertaking efforts of sufficient magnitude to fulfill the promise remains to be seen.

Despite the potential benefits of collaboration, the contributions in this volume attest to the difficulty associated with creating and maintaining collaborative relationships that support significant, sustainable research leading to transformations in organizational performance and meaningful additions to the body of scholarly knowledge. The challenges of collaborative management research only intensify as we increase the scope of concern from understanding single organizations to understanding complex networks of organizations and even societies. As more players with vested interests enter the equation and the stakes become higher, achieving progress becomes more difficult. Improving productivity in a single organization is difficult, but achieving better outcomes for a region, segment of society, or entire industry is a daunting task.

A pessimist might argue that the most important issues facing the world today are the least amenable to collaborative resolution. We take a view that is both more optimistic and pragmatic. Optimistically, we believe that, given time and continued effort, the field of collaborative management research will overcome current obstacles in order to make a greater contribution to management at the individual, organizational, and societal levels. Pragmatically, we would argue that many of our most vexing challenges can only be resolved by research that is truly collaborative, because collaboration is required to both understand and change the dynamics underlying complex systems. In this introductory chapter, we discuss the importance of collaborative management 
research, define the scope of our endeavor, and preview some of the exciting ideas readers will find between the covers of this book.

\section{FRAMING THE ISSUES}

The first section of the book helps us understand the nature of collaborative management research. From our perspective, we believe it is important to understand what it is that we are addressing here and, just as important, what we are not. The phrase "collaborative management research" is not universally understood or applied in a uniform fashion by managers and academic researchers. If we deconstruct the phrase, we gain insights into a field of endeavor that is only beginning to come into sharper focus.

\section{Collaborative}

By collaborative we intend to signify research efforts that include the active involvement of managers and researchers in the framing of the research agenda, the selection and pursuit of methods, and the development of implications for action. Our definition of collaborative does not impose the requirement of an equal partnership in each of these activities, although we understand that a more equal partnership would be ideal (see Lincoln \& Guba, 1985, and Reason, 1988, for a discussion of the benefits of collaborative inquiry). At the heart of this endeavor is "collective inquiry," which is the joint pursuit of answers to questions of mutual interest through dialogue, experimentation, the review of knowledge, or other means. To be more precise, management engages in collective inquiry in order to get a better understanding of a certain issue or phenomenon by means of input of scientifically valid knowledge from researchers. Similarly, scientists engage in collective inquiry in order to get a better understanding of a certain issue or phenomenon by means of knowledge regarding practice from managers. If two parties don't share a fundamental interest in learning, there can be no collective inquiry and no collaborative research. We should note here that the parties may be motivated by different aspirations. Managers may desire quick fixes to pressing organizational problems while researchers care more about generalizable solutions to widespread issues. Still, if there is a coming together of interests to learn about some phenomenon occurring in the organization, collective inquiry may be not only possible but also the best means for achieving the aspirations of both.

Collaborative research goes beyond collective inquiry because inquiry itself does not require collection and analysis of external data in addition to data that the interlocutors possess in their heads or close at hand. A well-performed professional medical consultation is an illustration of what a collective inquiry could be. The patient tells the M.D. how his ailment developed and his symptoms and feelings, while the doctor gives a recommendation to the patient based on what she hears, based on her former experience and what she has read. The patient may walk away from the meeting with new insights into his troubles and how he could deal with them. The doctor may be left with not only payment but also an insight that could lead to testing new insights about how to treat other patients. A powerful example of collective inquiry in the context of management is Chris Argyris's method of engaging managers in a conversation that helps them understand how their single-loop reasoning chains them and how double-loop learning can permit them to find creative new ways of acting (see Werr \& Greiner, Chapter 5, and Argyris \& Schön, 1982).

We think of collective inquiry as the core activity that takes place in the study of a single organization or system, as managers and 
management researchers seek to understand the naturally occurring or intentionally induced effects of different organizational arrangements on behavior and performance. As scientists like Argyris and Freud have shown, the inquiry process can itself generate scientifically useful data that result in radical reorientations of practice, methodology, and theory. The collective inquiry process may often be extended into a process of collaborative research. There are two reasons for such an extension. One is to avoid the cognitive traps of reflexivity and superstitious learning stemming from groupthink and the confusion of causes and effects that easily take place in a closed system. A second is to be able to benefit from the experience of others and the greater variability of larger systems. Collaborative research concerns the dual and intermingled processes that are going on as an organization is undergoing development by adopting new structures and processes while researchers attempt to provide knowledge, which is not readily accessible in the organization, from scientific sources or by gathering and analyzing observations.

The scholarly knowledge can be about the process through which organizations undergo inquiry and development or it can be about content: the frameworks, solutions, and features that lead to a system being more effective in accomplishing its goals and fulfilling the aspirations of its stakeholdersand the boundary conditions, which are requisite features of such approaches. More about this when we discuss what we mean by "research."

Different degrees of collaboration are possible, and we see examples of this throughout this volume. At one extreme, collaboration may be limited to access to an organization for data collection, with minimal interest on the part of the manager in framing the questions, methods, and conclusions of the research. Certainly, there is some threshold below which collaboration is no longer genuine, and we should at that point cease to describe the effort as collaborative research. At the other extreme is collaborative research that seeks not only to produce knowledge but also to fundamentally transform a system via the research process. In these efforts, collaboration is a necessity and occurs broadly, deeply, and almost continuously over the course of the project. In between these two extremes are instances of selective collaboration, in which only a few members of management are deeply engaged in collaborative inquiry activities around a narrow topic, usually without there being a strong agenda to transform the entire organization in fundamental ways.

Collaborative management research is therefore defined as an emergent and systematic inquiry process, embedded in an agreedupon partnership between actors with an interest in influencing a certain system of action and researchers interested in understanding and explaining such systems. The collaborative research process integrates scientific knowledge, methods, and values with practical knowledge, ways of working, and values. One aim for the new knowledge generated through the collaborative process is that it should be actionable for those who in practice intend to influence the system. Another aim is that the researchers should be able to claim that it is scientifically relevant and useful for the development of their field.

The collaborative research process is difficult to master because values and aims of science and practice are often experienced as antagonistic. A balance must nonetheless be struck between dependence and independence of the actors, between the quest for generalizable patterns and the development of specific applications, between timeconsuming analysis and quick fixes, between conceptual reasoning and concrete problem solving, and between the emphatic advocacy of insiders and the disinterested inquiry of outsiders. Collaborative research requires the formation of a "community of inquiry" 
through a partnership among individuals with varying priorities and goals.

As ideas are tested and applied, collaboration doesn't stop, but the parties involved may be augmented by others with an interest in the outcomes of the research. This is true not only in the economic and management sciences but to a high degree in the engineering area, where research and practical applications are often closely integrated. As is illustrated by Walshok and Stymne (Chapter 15), the ongoing dialogue between scientific research, industry, and other interested parties increases the chances for significant breakthroughs. We share this view and hope that this volume adds additional voice to the argument that research conducted with the involvement if others, even if more difficult to control in an experimental sense, holds tremendous potential for the advancement and application of knowledge.

\section{Management}

While one would think that the definition of management is obvious, our most vociferous debates have been about the legitimate scope of our work with regard to this term. Indeed, at least one invited author declined to participate because he associated the term management in the title of the book with capitalism and all its ills, rather than holding a broader interpretation of the term that could include the management of not-for-profits and even political or economic systems. Rather than settle the debate by narrowing ourselves to a definition of management as "what MBAs do," or accepting a broad definition of management as "any process that involves organizing a system," we elected to leave the issue open and allow our authors to help us define the field of inquiry through their submissions. The result, as one might expect, was that we were pulled toward a somewhat broader definition of management than we had in mind at the outset.
Management can be carried out by an individual or a team, or even by groups of people who are not formally managers-for example, by representatives of various stakeholder groups. An example is provided in the contribution by Apel, Heikensten, and Jansson, Chapter 18 in this volume, which discusses how several central banks attempted to influence one country's entire economy by managing its monetary policy. Management therefore can be thought of as a noun: an individual or collective group of actors who aspire to influence the behavior or performance of a system. Management (or managing) also can be a verb: the practice of those actors. In this sense, management signifies an art or practice, that is, what managers tacitly or explicitly know and believe about how to go about managing an organization or complex system.

As evidenced by the contributions here, collaborative management researchers are not in strict alignment about the subjects of their inquiry. To some, like Boyatzis, Howard, Rapisarda, and Taylor (Chapter 11), the focus is on improving the capabilities of the individual manager. To others, like Kolodny and Halpern (Chapter 13), the concern is with improving the performance of an organization; and for some, like Tandon and Farrell (Chapter 14), the reference is to a class of organizations and their influence on society as a whole.

Nor are we in complete alignment regarding the objects of our research. Stebbins and Valenzuela (Chapter 23) discuss research in a single organizational setting, and Mohrman, Mohrman, Cohen, and Winby (Chapter 24) describe related studies in multiple organizations. Coghlan and Coughlan (Chapter 21) and Huzzard and Gregory (Chapter 16) focus on organizational networks; Walshok and Stymne (Chapter 15) and Tandon and Farrell (Chapter 14) address regions; while Roth (Chapter 17) and the ARC Research Team (Chapter 22) examine research networks. 
We can easily imagine a two-dimensional matrix in which we study the actions of different types of managerial actors (individual, organizational, systemic) in different settings (a single organization, networks of organizations, systems, regions, or communities); but those two dimensions would be too simplistic to cover the diversity of research we see in practice. We would need to add at least one more dimension that addresses the aspect of management studied: specific managerial actions, systems of management processes affecting organizational culture or performance, or coordinating mechanisms among networks of organizations.

So, the question of what management is and how one should approach its study is open to debate and experimentation. Even when we try to simplify things by studying management in a single organizational system, we are confronted by the complexity of modern organizations. There are multiple levels of managers in a system, and rarely are they aligned in their views or actions up and down the chain of command or across the enterprise. There are formal and informal leaders who vary in their level of participation and influence in shaping decisions depending upon the issue under consideration. Individual leaders join and leave the organization, and even systems of management change over time, sometimes gradually and occasionally in dramatic ways. Interventions are not uniformly undertaken or adopted, nor are they carried out uniformly across the organization as planned. Local adaptation to different cultures or customer groups can create variations in management methods across units and cause centrally initiated strategies to be rejected or adapted beyond recognition. Even in a single unit close to headquarters, interviews of a random sample of managers will reveal different philosophies and beliefs about what effective management entails. Despite the application of highly collaborative research methods described in some of the contributions here, understanding what is really going on and what management actions or systems of management processes are really responsible for causing variations in performance is extremely difficult.

The promise of collaborative management research is that through multiple studies, the accumulation of knowledge over time about different aspects of management and across different types of systems will help clarify when and how managerial actions can make a difference. Continued attempts to learn from experience, apply knowledge in the form of new innovations, and thereby confirm or disconfirm assumptions will result in the gradual accumulation of wisdom that can be captured by scientists and applied by new generations of managers. Although individual studies may not be appreciated or even come to the attention of more than a few managers, the accumulation of knowledge over time can produce changes in widely held paradigms that are interesting and well-publicized, and that may eventually influence how management is taught and practiced (Kuhn, 1962).

\section{Research}

This brings us to the last of the terms to be defined. What is it that we mean by research? When does a casual conversation between a research scientist and a manager suddenly become a moment of collective inquiry leading to fascinating insights that challenge established management science and justify serious rethinking of corporate policies? How rigorous do data collection methods need to be to qualify as legitimate research, as opposed to being biased reflections on a momentary event by well-intended but unsophisticated partners in a collaborative research alliance? These are important questions that, as editors, we found ourselves unable to answer with precision.

For many centuries, the purpose of conducting research has been to enable us to better 
understand the world about us, and through that understanding, improve the quality and sustainability of our lives and endeavors. In the physical sciences, research has relentlessly pursued ways to expand our knowledge about the characteristics and functioning of the tiniest processes and particles as well as of the universe as a whole. Long ago, we abandoned the view of a classical Newtonian ordered universe. New hypotheses are constantly being suggested, methods for testing them are being developed, and theories that experiments do not contradict are provisionally retained.

Management science and many of its books on research methodology try to live up to an image of physical science that even physical science does not entertain. In reality, the story of highly controlled experimental laboratory research is a lot messier than is often portrayed. In order to carefully eliminate the influence of other variables, experiments are conducted in ways that remove the influence of significant factors that operate in the real world. This can make transfer of knowledge from the laboratory to the outside world difficult.

As Kaplan (1964) has pointed out, methodology books deal mainly with the logic of verification that results when observations are collected in the correct manner. The social sciences use reliability and validity as the criteria for objectivity. However, trustworthy observation by itself does not really move science forward. The main mover is discovery. The logic of discovery builds on intuition, serendipities, chance encounters, and power games and depends on whom you collaborate with. The logic of discovery is almost never described in methodology textbooks. It is time that management science take the logic of discovery seriously (see also David \& Hatchuel, Chapter 2).

As we move into the human realm, research conditions become more difficult to control. In medical research, for example, variation in the previous condition of patients undergoing a particular treatment or operation can greatly influence the outcomes observed from a given medical intervention. So may a variety of other factors, such as age, metabolism, genetics, race, gender, and sensitivity to dosage levels. The "error" introduced into research studies by these types of human variations is unavoidable. To minimize risks to patients, research methods in the medical sciences have evolved over the years to include early studies done in other species, followed by preliminary studies on small samples of carefully selected human patients, and finally larger clinical trials. Despite these efforts, variations in treatments of specific individuals still produce a range of results, some of which are not predictable and can be quite serious. The benefits of medical advancement for the many outweigh the risks to the few, but these risks are carefully monitored by government bodies and professional groups who make certain that researchers pay strict attention to accepted research practices.

As we turn our attention to research in the social sciences having to do with individual human behavior, the behavior of groups, and ultimately the actions of organizations and systems, we find that the challenge of remaining "rigorously scientific" becomes even more difficult (Gergen, 1982). The ability to "control" extraneous factors affecting behavior in natural settings is limited, making it more difficult to draw cause-effect conclusions between specific variables of interest. The problems that interest us the most aren't amenable to laboratory experiments to begin with; if we are concerned with the impact of different work systems on productivity, for example, we find it difficult or impossible to bring an entire organization into the laboratory where we can control everything that takes place. Instead, we might design pilot plants that operate on different principles than traditional plants and assume the differences 
in results we observe are due to design features rather than exogenous variables like the quality of the people working in the plant or the use of improved technical controls. As noted by Stymne (2006), collaborative management research often must rely on testing a model in practice rather than conducting controlled experiments:

Another reason for experiments not being used in management science is that the natural science experiment tries to control the impact of the result of all factors other than the experimental treatment. A firm is an ongoing activity and there is no way to control everything in it or around it. However, the manager and the researcher can together establish a model of how the manager's world hangs together. The outcome of the action under study can be evaluated against the model, and conclusions can be drawn about both the impact of actions and the appropriateness of the model. In natural science, rats are often used in experiments but, even if rats are intelligent animals, our means of communication with them are quite limited. In contrast, conceiving action in firms as quasi-experiments makes it possible to use the managers' intelligence and insights as partial substitutes for laboratory controls. A whole chain of interpretation and translation processes has to take place before the responses from the rat can be used for a drug that can help an ill person. Contrary to rats, managers have the ability to interpret the consequences of their action and incorporate that interpretation in their articulated model of future action. (p. 267)

Added to the difficulty of achieving control in social science research is the problem of overcoming reflexivity, or the impact of the scientist's methods of observation on what he or she is observing. A study of motivational factors that affect performance, for example, could falsely conclude that higher pay is associated with greater output, when in fact simply the effects of being observed by others (the so-called "Hawthorne effect") could have something to do with the results. Although it has long been recognized that this is not entirely possible (Mitroff, 1974), the natural science researcher is supposed to remain detached from and be able to observe the objects under study using tools, such as a telescope, that don't influence the behavior of those objects. The social science researcher, and especially the collaborative management researcher, cannot remain detached from the people under study. The act of observing, intervening in, or collaborating with managers of systems to conduct research changes those systems in ways that are impossible to fully comprehend and, furthermore, vary from organization to organization or system to system. Each collaborative management researcher, in seeking to add practical value through his or her work with the system, will recommend courses of action that are intended to influence the outcomes observed in a positive fashion. As they interpret what they observe, these researchers will not be able to completely detach themselves from their theories and biases, which makes objective assessment of outcomes difficult. Third parties can be brought in as objective observers to mitigate this effect, but the influence of the researcher on the behavior of those under study can never be isolated completely, leaving open the question of just how generalizable the findings may be.

As we conduct research designed to understand organizations and even more complex human systems, we are struck by the pervasiveness of the conundrum of reflexivity in systems that are essentially artifacts-creations of their designers and participants (Simon, 2001). Social orders are socially constructed in practice (e.g., Berger \& Luckmann, 1966; Bourdieu, 1990). We design our organizations over and over in the course of making sense of what is happening 
as we carry out the work of management and the transformation work of the firm (Weick \& Quinn, 1999), and as various individual and collective actors pursue their purposes. Giddens (1993) addresses this as the "duality of structure," which refers to the notion that social order or institutional properties of the social system are created by human action and in turn serve to shape human action. Thus the various participants in any collaboration, in pursuing their goals for the collaboration, cannot help but change the phenomena that are being studied, because that is the very nature of organizing.

Finally, we should note that collaborative management research struggles with the question of ethics just as do other scientific undertakings. Medical researchers must decide on when it is "safe" to bring a drug to market, trading off the greater degrees of certainty that come with larger clinical trials against the knowledge that patients will die (and profits be delayed, a counter-ethical pressure of the corporate sponsorship of research) if the drug is not made available as quickly as possible. In collaborative management research, scientists must decide whether to offer their help to make an intervention in an organization succeed or to let the course of events unfold naturally, even if that would mean the organization under study would be more likely to fail. The former is more in keeping with the spirit of true collaboration, while the latter is more in line with scientific doctrine and the pursuit of "objective truth." If, in following his or her collaborative instincts, the scientist becomes so involved in the intervention at a personal level that the results reported could never be repeated in another setting, what is the value of this study to society? On the other hand, if scientists stand by and watch managers fail in high-risk organizational change programs, what would be the incentive for managers to collaborate?

Despite these many challenges, the pressing nature of problems confronting our organizations, systems, and societies forces us to carry on in our search for better management solutions. As in other sciences, the "truths" that we can expect to find in one organization or one study will be neither universal nor constant. Generalizability is therefore not a very powerful criterion of scientific value in management sciences. It is a vain hope to understand how people behave in organizational settings in general, but it may be more fruitful to investigate how people act in different types of organizational settings and under different conditions. Over time, we can build on what we learn across organizations and systems to build a more nuanced, deeper, and broader understanding of the phenomenon of organizational behavior.

We are interested not only in data that describe things as they are, but in understanding why things are that way. Collaborative management research respects the contextual character of management knowledge. It also respects the fact that organizational and other managed systems are artifacts designed in social processes. Investigating specific systems by including their designers therefore makes good sense. Collaborative research is certainly not the only way to generate trustworthy and useful knowledge in management science, but it has many advantages as a complement to other approaches, by which we can continue to add to the body of knowledge concerning the effectiveness of management behaviors, systems, and approaches.

There are management researchers who study important questions related to the appropriateness of different strategies or leadership systems without ever setting foot in an organization. Simply by studying records, we can learn a great deal about classes of organizations that have thrived while others have perished, or about the success of leaders with different levels of preparation for their jobs. There are other researchers who generate important insights by running managers 
through simulations and observing their reactions to various types of scenarios or inputs. Still others use surveys as their preferred method to gather data from large numbers of people across different organizations and geographies, in the hope that through an analysis of the relationships among the variables measured, they can arrive at tentative conclusions about what kinds of attitudes or self-described behaviors are associated with different kinds of outcomes, such as absenteeism, turnover, acceptance of change, or the quality of decision making. We applaud all of these researchers and support the need for a multimethod approach to inquiry in the field, because we recognize that in the complex, interconnected, ever-changing world that is our reality, no single approach can ever proclaim that it has led us to an absolute truth. By no means are we making a case that all management research must be collaborative; but we do insist for our purposes here that collaborative management research must involve research.

At the most fundamental level, what all forms of research share is the desire to understand something of importance through the use of means that limit the likelihood that we will reach false conclusions. The world is full of people with opinions about things, whether they are speaking about diets, weight-loss plans, management techniques, or ways to bring about world peace. What researchers aspire to add to the discussion of these topics is "objective data," or, rather, to express beliefs justified by earlier research, by observations gathered through rigorous methods, and arrived at by a better application of formalized logic than one would casually use in forming an opinion about something based on one's personal experience or informal conversations with others.

This brings us back to the questions at the beginning of this section. How can we tell when someone is casually formulating an opinion as opposed to conducting "research"?
There are no hard-and-fast answers to this question. The social sciences have never agreed to impose finite standards upon those who claim to be conducting research. Professional peers, including professors or editors of journals and books (like ourselves), make decisions about the quality of work that deserves to be published or receive credit. Publishers of books make decisions about what they believe will sell, or whether scientific work meets the standards by which they feel their reputations will be protected. But these standards are not published anywhere, and they vary from institution to institution and person to person. When someone publishes a popular book on management with little or no objective research behind it, scientists bemoan how easily managers can be duped into accepting a point of view that is based on a case study or two and largely represents the author's unscientific opinion. Yet there are case studies in this volume that, while carefully done and thoughtful in nature, would be hard to distinguish from the cases used in those best-selling popular books, at least from a methodological perspective. One thing that does help us maintain a certain level of rigor in management research is that we expect our work to be reviewed by our professional peers. This is not always the case among popular authors. Aside from this important caveat, the definition of what constitutes an "acceptable" level of rigor in management research must be formulated with an open mind toward research methods that are different from those in use in the physical or medical sciences.

Over the past hundred years, many approaches have been employed to study the effects of different organizational arrangements, leadership behaviors, and management systems. These methods have varied from detached observation to "controlled" experiments to surveys to active intervention. All of these constitute approaches to research that, if done well, can be valid, even if not perfect. 
Some methods of research are better at answering certain types of questions than others. Surveys, for example, are more useful for gathering reactions of large numbers of people to a specific managerial practice than conducting hundreds of controlled experiments. Controlled experiments, on the other hand, allow researchers to do a better job of isolating the effects of different leadership styles on the quality of decisions reached in a small group. No one way of conducting research can possibly hope to answer the full range of questions that we must ask ourselves if we are going to continue to advance the ability of managers and organizations to tackle the important issues that confront our workplaces, economies, and societies today. Therefore, it should not surprise us that the contributors to this volume employ a wide range of research methods in conducting collaborative management research, as they work together closely with their counterparts to learn about different types of phenomena. It is therefore less important to define research here in terms of specific methods than in terms of the effort that is made to achieve rigor in guarding against false conclusions.

We have had debates among us as editors in regard to the level of rigor that is required for a contribution to be considered a valid piece of collaborative management research. If we brought our many contributors into the debate, it would be even more difficult to settle. It has been our experience throughout our careers in the field that the tension between observing organizations in their natural state and applying scientific rigor to "control" the impact of extraneous variables on outcomes of interest is always present. It is never satisfying to simply say, "We know good research when we see it," because we recognize that our standards and those of others will vary. Yet due to the inherent limitations in the study of human systems, we also realize that there can be no absolute standards that everyone can apply across the board to judge the goodness of different research efforts. We are forced to acknowledge that our definition of research is not as precise as any of us would like it to be, and that for now we will have to trust our judgment to determine when an author has paid "sufficient attention" to eliminating the likelihood of drawing false conclusions by applying scientific methods to their work.

\section{Collaborative}

\section{Management Research}

If we bring together our views of collaboration, management, and research, we arrive at a statement of the focus for this volume. Collaborative management research is an effort by two or more parties, at least one of whom is a member of an organization or system under study and at least one of whom is an external researcher, to work together in learning about how the behavior of managers, management methods, or organizational arrangements affect outcomes in the system or systems under study, using methods that are scientifically based and intended to reduce the likelihood of drawing false conclusions from the data collected, with the intent of both improving performance of the system and adding to the broader body of knowledge in the field of management.

\section{RELATED SCHOOLS OF THOUGHT}

Collaborative management research, as advanced in this Handbook, shares common views of the philosophy of science with other schools of thought that have emerged in the social sciences over the past decade, all of which involve some form of collaboration between researchers and those being studied. Proponents of these methods have raised similar questions concerning the ontological and epistemological foundations of collaborative research and have contrasted collaborative 
research with scientific methods associated with positivistic philosophy (e.g., Susman \& Evered, 1978; Reason \& Torbert, 2001).

To the extent possible, it is important for us to distinguish collaborative management research from these other forms of collaborative research, such as action research or participatory research, in order to make the unique added contribution of this volume clear. While it would be redundant here to retrace in detail the comparative discussions of eight different collaborative research methods offered by Shani, David, and Wilson (2004) and the dozen reviewed by Coghlan and Brannick (2005), it is probably of value to remind readers of some of the conclusions drawn from these efforts.

First, it is important to note what all these approaches have in common. All of the emerging collaborative orientations attempt, in one way or another, to combine some features of both "inquiry from the outside" and "inquiry from the inside" (e.g., Evered \& Louis, 1981). They also share the value that "knowledge production" and "action" are not set apart as two separate processes. Finally, as our basic definition of collaborative research indicates, all share the approach that some kind of research team composed of actors from within and outside the organization is created to work together and learn using methods that are scientifically based.

What makes collaborative management research unique and different is that it is interested specifically in understanding the influence in organizations and other complex systems of behaviors, actions, and purposeful designs that are intended to manage the system toward intended outcomes. In contrast, action research has historically addressed a much wider scope of social science issues, beginning with Lewin's classic studies on the impact of participation on the adoption of new behaviors in small group settings. Action science and developmental action inquiry (Argyris, 1980; Argyris, Putnam, \& Smith, 1985; Argyris \& Schön, 1989;
Torbert, 1976, 1999) are primarily concerned with the cognitive processes of individuals' theories-in-use, which are described in terms of Model 1 (strategies of control, self-protection, defensiveness, and covering up embarrassment) and Model 2 (strategies eliciting valid information, free choice, and commitment). Participatory research (Brown, 1990; Tandon, 1989; Whyte, 1991) has been associated with engaging members of complex systems to bring about changes in society and has been less concerned with the functioning of single organizations. Each of these schools, and others not covered here, has its disciples and detractors.

What collaborative management research seeks to add to these emerging approaches is the value that could be gained when practitioners and researchers engage in a joint undertaking where each partner takes some responsibility also for the other partners' learning and knowledge. The reason for this mutual sharing of responsibility is not only altruistic but also pragmatic. The practitioner will gain if the researcher succeeds in formulating an innovative management model that will give an advantage over competitors. The researcher will gain if the practitioner tries out some of the advice given and if scientifically interesting observations of the process can be made. We suggest a change in the perspective on the task of management. It implies less of a focus on the characteristics and behavior of individual leaders but emphasizes the mechanisms for the creation of a useful knowledge base for managerial action. We hope that the principles and examples of practitioner-researcher collaboration and interaction offered in this Handbook will provide epistemological justification and useful methodological advice as well as inspiration for engaging in collaborative research.

We now turn to an overview of the Handbook. We will provide a high-level overview here and rely on the sections and the chapters to speak for themselves. 


\section{SECTIONS OF THE HANDBOOK: A PREVIEW}

\section{Framing the Issues}

The first section is intended to provide multiple viewpoints on the issues we have outlined above. Following our discussion, Albert David and Armand Hatchuel (Chapter 2) address the challenges inherent when knowledge is generated from collaborative efforts in the interplay between aspects that are immediately actionable and those that contribute more broadly to universal theories of management. Their chapter proposes a framework for understanding the issues involved in moving back and forth between actionable knowledge and universal theory. Using the dimensions of discovery versus validation and theoretical versus applied, they distinguish among four types of contributions that collaborative management research can make: (1) the discovery of new theory, (2) the invention of new models for application in practice, (3) capturing new knowledge from practice, and (4) improving upon known theory and practice.

Next, Tenkasi and Hay (Chapter 3) transport us back in time to remind us of Aristotle's support for integrating theory and practice. By studying 11 instances of collaborative management research, they discovered six unique strategies used by scholars and practitioners for interrelating theory and practice: framing, influencing and legitimizing, sense making, demonstrating, turns, and scaffolding. The authors describe each of these methods in detail using examples, and then they discuss overall implications from their analysis for the design of collaborative management research efforts.

Bartunek (Chapter 4) takes us on a journey through the realm of "insider/outsider research." Using examples, Bartunek demonstrates how the roles of insider/outsider researchers are shaped throughout the steps that take place in most efforts of this kind.
She notes that the roles are socially constructed and much more malleable than one might imagine, with the boundaries for both academics and practitioners stretching toward one another. What's more, Bartunek points out that insider/outsider relationships are not without conflict and other complications that make the creation and maintenance of a collaborative relationship challenging. Again using examples from actual efforts, Bartunek reveals these issues in compelling fashion before offering some guidelines on how to create more effective insider/outsider relationships.

Werr and Greiner, in the next contribution (Chapter 5), explore the dynamics that often limit collaboration in research among managers, academics, and consultants. They view all three as producers of management knowledge and ask what they can learn from each other. Werr and Greiner suggest that there is a strong potential for collaboration within the triad manager-researcher-consultant but also acknowledge the institutional forces that make such collaboration difficult and discuss how these forces may be overcome. The authors use interviews with three noted academics who have built important contributions to management knowledge through their consulting activities- Edgar Schein, Chris Argyris, and Edward Lawler-to illustrate the mechanisms that can be employed to reduce the tensions academics and consultants experience when collaborating in the production of more valid and useful knowledge.

Based on this set of framing chapters, it's clear that the topic of collaborative management research is more interesting and challenging than we might have imagined at the outset of this journey. The sections that follow make the journey all the more worthwhile.

\section{Mechanisms and Processes}

The next section of the book introduces us to a variety of approaches to the conduct of 
collaborative management research. McGuire, Palus, and Torbert (Chapter 6) offer us the theory of developmental action inquiry, along with the notions of engaging in 1st-, 2nd-, and 3rd-person research/practice, single-, double-, and triple-loop learning, and an interweaving of collaborative research and collaborative practice. In contrast to modern science-which offers a model of 3rd-person research "on" "subjects" for scientific publication alone rather than for their own development and enlightenment-developmental action inquiry is a model of research that requires a high voluntary commitment and collaboration by participants. The authors identify a specific sequence of action-logics through which any human system can (but may not) transform. McGuire, Palus, and Torbert illustrate how developmental action inquiry is applied through a longitudinal case study of individual, interpersonal, team, and organizational transformations. They conclude that the special challenge of developmental action inquiry is that it cannot be routinized. Its highly collaborative and introspective nature requires that the general theory be understood but that specific approaches be developed when engaging each unique individual or system.

In their second contribution to this volume, Hatchuel and David (Chapter 7) note that in the first hundred years of management research, many of the main revolutions in management have come from innovative firms and not from academic research. To enhance the potential for academia to contribute to future breakthroughs, Hatchuel and David ask us to consider intervention research in management, or IRM. Using Renault and other examples of the application of IRM techniques, the authors help us understand the conditions that are necessary for effective industry-academic collaboration. Hatchuel and David outline some critical principles that IRM researchers must follow, as well as the importance of distinguishing between espoused management practices and management practices in use.

Docherty and Shani, in the next contribution (Chapter 8), outline the processes through which collaborative management research can help organizations become more capable of learning. In order to make collaborative research more than an event, Docherty and Shani argue, collaborators should focus on the design of more permanent mechanisms for organizational learning as a part of collaborative management research efforts. Just as there are many types of organizational designs, there are also many ways to design and manage organizational learning mechanisms. These mechanisms can be cognitive, structural, or procedural in nature, or some combination of the three. The authors argue that collaborative researchers should shoulder the responsibility of facilitating the design of learning mechanisms that are an integral part of the scientific discovery process and learning. Using a collaborative research project with Skandia Corporation, the nature and tapestry of the learning mechanisms used is illustrated and the role that they play in the collaborative management research project is discussed.

Holmstrand, Härnsten, and Löwstedt (Chapter 9) describe an additional enhancement to collaborative research methods, that of the research circle approach. Underlying this approach is a deep conviction, long held among the Swedish people who gave birth to it, that for knowledge to have maximum benefit, the processes for creating it must be democratic. The research circle is described as a forum where organized knowledge construction takes place and knowledge development in cooperation with all participants is established. The circle starts its work from a multifaceted problem that allows the participants involved to work collectively on its resolution. As one might imagine, the dynamics 
of bringing together people of widely differing backgrounds and research capabilities to generate knowledge regarding a problem can be challenging. They conclude that despite its challenges, use of the research circle method allows the generation of knowledge that could not be obtained through more traditional research methods.

The final chapter in this section, by Mirvis (Chapter 10), examines three different forums in which collaborative management research took place. Each forum involved multiple companies with their distinct as well as common interests and multiple researchers with different agendas. The work concerns how research and practice interests are defined, combined, and realized in a collaborative, interorganizational relationship. Mirvis compares the examples in order to provide insights into why the participants chose to collaborate in learning, how the forums were structured to produce knowledge, and what the outcomes of the forums were for the people and organizations involved. Of particular interest is how learning occurs between academics and practitioners through processes of knowledge transfer, translation, and transformation. Mirvis concludes that academics should understand their goals before joining a particular forum, since not all are well suited to the generation of traditional scientific knowledge.

Collectively, the contributions in the "mechanisms" section of the book help us understand that collaborative management research is an evolving field and that we are learning from our experiences as we continue to invent new ways to do this work. While there are certainly identifiable themes, such as the democratization of knowledge and the focus on higher level awareness of the processes and structures that we are using to learn, there can be no rigid epistemology of collaborative management research at this time. The chapters in this section suggest that each participant brings different knowledge about practice, about the scientific discovery process, and about what might work. The chapters also illustrate the diverse approaches, mechanisms, and processes that have emerged in the field and the need to investigate alternative approaches for those interested in pursuing collaborative management research.

\section{Exemplars: Cases and Projects}

Perhaps the best way for us to advance the state of knowledge in the field of collaborative management research is through its continued application. In this section, a wide variety of efforts are discussed that provide interesting insights into the current state of the art. Boyatzis, Howard, Rapisarda, and Taylor (Chapter 11) lead off with a discussion of collaborative research at the level of the individual manager. After reviewing the literature concerning the effectiveness of managerial coaching interventions, they note that coaching is most effective when it involves the formulation of a joint plan for inquiry. Using an evocative story of one manager going through a personal transformation during coaching, Boyatzis et al. conclude that coaching is collaborative, contagious, and mutually transforming; when done well, the coach learns as much as the manager.

In the next contribution, Olascoaga and Kur (Chapter 12) explore the application of a method they call "dynamic strategic alignment" in a Mexican manufacturing company. The approach included the collection of data through surveys and interviews; the data was shared with various groups of people throughout the organization in order to better align people's efforts with the changes that were occurring in the firm. Working closely with representatives of the organization, the actual approach for the collaborative research changed almost continuously as conditions changed and new insights emerged. While the authors were able to 
measure important results from this effort in terms of goal alignment in the organization, they concluded that in the long run the learning they and the organization gained about managing change through collaborative research was ultimately much more valuable.

Kolodny and Halpern (Chapter 13) review the broad global evolution of sociotechnical systems practice as well as specific Canadian cases to demonstrate that the tradition of collaboration and knowledge sharing has been a part of the field of sociotechnical systems since its inception. The authors provide a primer on the field for those who might not be familiar with its rich history and use recent applications as evidence that the concern with collaborative research among managers, academics, and practitioners has not faded over time. The authors do note that many of the early founders of the field were associated with institutes rather than universities, and raise the question of whether the increased distance between academics and industry may be partially to blame for the comparatively slow evolution of new forms of collaborative management research.

Tandon and Farrell (Chapter 14) examine a group of Indian nongovernmental organizations dealing with the role of women in society. As the authors note, women's marginalization, exclusion, and deprivation are pervasive in many societies around the world due to a wide variety of cultural and religious practices and taboos. A group of Indian nongovernmental organizations was dedicated to changing the role of women in society, beginning with a review of the role of women in their own organizations. Using collaborative research methods, what the organizations learned about themselves was not always easy for them to accept, yet the knowledge proved to be transformational. Building collaborative and learning-processoriented inquiry processes on the theme of gender mainstreaming made it possible for organizational teams to discover their own reality of structures and practices that were gender-fair or unfair. Interpretation of data by the teams themselves made it possible for the analysis to be owned by the organizations, thereby enhancing possibilities for fundamental changes to happen.

Walshok and Stymne (Chapter 15) discuss how the collaboration between science and research can be organized on the regional level in order to result in commercially highly successful product innovations and important scientific progress. The examples they cite are fetched from engineering and life sciences and intended to demonstrate the fertility of collaboration between practice and scientific fields not limited to management research. By describing the region as a playing field for the game of collaborative research, they point out that science-practice collaboration not only is an issue for specific projects but can be successfully institutionalized in supraorganizational systems.

Huzzard and Gregory (Chapter 16) discuss the use of collaborative research methods in a trade union setting. Most industrial relations scholars have tended to focus on levels of analysis of a rather macro nature, seeking to describe trends and explain structural relationships rather than seeking to intervene at a more local level. This study adopted collaborative methods to study a number of important issues of concern to both labor and management.

The authors show how single-site cases generated knowledge outputs that were fed by collaborative researchers into a broader network spanning some eight countries all with different institutional contexts and industrial relations legacies. Dialogue and experiences from the latter, in turn, generated refined knowledge outputs that were then taken back to the single-site settings. The collaborative researchers were able to establish learning forums and provide training that enabled labor and management 
to invent rather than simply negotiate new solutions to issues of shared concern.

Next, George Roth (Chapter 17) examines the rich history of company-sponsored research conducted with MIT. As the representative of the university in a key research program sponsored by Ford, Roth was able both to gain insights from his experience and to experiment with different methods of improving the collaboration between academics and managers. Roth is also able to stand back from his individual program to examine issues that industry-sponsored research presents to both companies and universities. While several of the insights that Roth gained from his own experience can be applied to improve these relationships, it is clear from his discussion that collaborative management research raises issues that can never be easily or fully resolved.

Providing a very novel perspective in this volume, Apel, Heikensten, and Jansson (Chapter 18) discuss how academic research has influenced monetary policy and economic development in Sweden. More specifically, after addressing the history of monetary reform policies in Sweden, the authors examine the forms of interplay between researchers and practitioners that have facilitated the application of research findings in the practical domain. The authors identify three such forms: informal interaction, formal collaboration, and internalization. The authors end their contribution with the inclusion of an interview with Professor Lars Svensson, Princeton University, who has combined a central role in the academic research on inflation-targeting policy with close contacts with monetary policy's practical side. His voice lends credibility to the viewpoint expressed in the chapter and provides yet another perspective on the importance of collaboration between academics and managers of complex systems.

Knights, Alferoff, Starkey, and Tiratsoo (Chapter 19), along the same lines as the contribution by Roth, investigated multiple instances of university-industry voluntary collaborative networks in the UK. Drawing on their own experience in one such network, the authors conclude that despite their popularity and benefits, maintaining industry-academic networks is painstakingly troublesome, because a diverse range of practical problems besets their continuity. As new economic forces threaten the viability of government-sponsored university research, the authors call for careful consideration of the value of voluntary collaborative management research networks among faculty and administrators who have tended to view such networks with a good deal of skepticism in the past.

Bammer (Chapter 20), writing with the Goolabri Group in Australia, describes the first stage of a process to promote the trading of information between disciplines and practice areas aimed at overcoming the ignorance and uncertainty that arises from a lack of sharing across disciplinary boundaries. Drawing upon their own experiences, they describe the evolution of what they call the integration and implementation sciences, which are intended to help tackle complex problems by focusing on crosscutting theory and methods to aid integration of knowledge from different disciplines and from practice, as well as the implementation of research knowledge in practice. While integration and implementation science holds out much hope, there are interesting challenges in its application that remain to be fully addressed.

\section{The Multiple Voices in Collaborative Research}

The "voices" section is intended to bring the subject of collaborative management research to life through the eyes of those who have lived the experience from multiple perspectives. While in other chapters some authors included the voices of the participants, 
in this section we specifically asked the authors to capture and share the various voices of participants. As you will read in the first four chapters of this section the authors captured and shared the voices in varying ways, ranging from formal interviews to including quotes from other papers where the participants had described their experience or their learning.

In the first contribution in this section, Coghlan and Coughlan (Chapter 21) describe a complex example of industry-academic collaboration in a European Union-funded effort to improve supply chain performance. The focus of the collaboration between the three industrial partners in three different countries, researchers from four universities in different nations, and two IT companies from two different countries was the discovery of models and learning mechanisms to improve supply chain performance. Together, these parties set out on a three-year collaborative learning improvement journey that involved overcoming organizational and cultural borders in several projects. Although the results of the projects were mixed, the voices of the managers involved offer an interesting perspective on the work and demonstrate the underlying value of collaborative management research in complex networks.

The next contribution, by the ARC Research Team (Chapter 22), is an inquiry into the nature of building a partnership between a college and its surrounding community in Israel. The Action Research Center (ARC) was initiated by the college and community for the purpose of learning together, initiating projects to stimulate mutual development, and generating new knowledge. The voices heard in this story are those of the authors of five different papers that were eventually combined to compose the account that appears in this volume. The insights gained through this very interesting form of collaboration have relevance for anyone who is interested in spanning the gulf between the ivory tower and the "real world." As in other contributions to this volume, many of the insights pertain to the deep challenges involved in maintaining a common agenda as critical decisions about the focus of the partnership and the efforts of its primary champions are debated.

Stebbins and Valenzuela (Chapter 23) discuss a collaborative research effort within the Pharmaceutical Operations department of Kaiser Permanente. At the outset, a group was formed as a microcosm of the pharmacy organization to create a new capability centered on democratic dialogue. Representative pharmacists, clerks, warehouse personnel, supervisors, and other pharmacy employees were to tackle problems not solved by the hierarchy. Two of our editors, Rami Shani and Susan Mohrman, interviewed the authors to learn more about the insights they had gained from watching the collaborative forum they had created develop and evolve over a period of 30 years. We know of very few collaborative research efforts with as long and rich a history as this. Obviously, those who are interested in creating sustainable relationships rather than short-term projects should pay careful attention to the description offered here.

Mohrman, Mohrman, Cohen, and Winby (Chapter 24) describe a program of collaborative research investigating the design of team-based organizations within the newproduct development environment in nine divisions of Hewlett-Packard (HP). This study was an intersection of the knowledgegenerating work of three communities of practice: researchers at the Center for Effective Organizations at the University of Southern California; members of the Factory of the Future group at HP, and personnel of $\mathrm{HP}$ engaged in leading and carrying out the development of new products, who were dealing with intense competitive pressures and were attempting to establish teams to improve this process. The authors describe the streams of theoretical and practical 
knowledge that converged in this collaboration, and the multiple trajectories of collaborative research that resulted. The chapter includes the individual voices of the authors, who interviewed one another for the purpose of this chapter.

The last chapter in this section, by Mohrman and Shani (Chapter 25), is an attempt to draw on the learning from the four chapters in the section. The authors argue that collaborative management research aimed at changing the dynamics and performance of a system must pay careful attention to the voices of the participants. The voices of the varied collaborators are rarely heard in reported research. Reflecting across the varied cases in which the voices of the collaborative management research actors were shared and explored, Mohrman and Shani identify and briefly explore four issues: alignment and purpose as the basis for true collaboration, the institutional context of collaboration, the voices around learning mechanisms, and the convergence of the language of practice and theory.

\section{Enablers, Challenges, and Skills}

The final section of the Handbook offers some thoughts about the state of the art of collaborative management research, including a critical appraisal of its strengths, weaknesses, and future potential. Adler and Beer (Chapter 26) describe and analyze experiences from building a tradition, a capacity, and a competence for R\&D in management in organizations and explore the value of these experiences for management research and management practice. The authors use 15 years of collaborations and experimentation, primarily by Truepoint and FENIX, as the basis for the chapter. Truepoint has primarily been using a systematic collaborative methodology known as strategic fitness profiling (SFP). FENIX has primarily been training executive Ph.D.'s (active managers in organizations working in research projects, writing scientific articles, and defending a Ph.D. thesis) and setting up collaborative workshops (management laboratories) and collaborative research projects exploring specific managerial challenges. Adler and Beer argue that $R \& D$ in management could become a functional process in complex organizations enabling the discovery, validation, and legitimization of new management approachesand simultaneously contributing to academic research meeting international standards.

Pasmore, Woodman, and Simmons (Chapter 27) argue that to make collaborative management research more valuable to the parties involved, it must become more rigorous, reflective, and relevant. After briefly reviewing the evolution of collaborative management research and the definition of scientific methods, the authors define rigor as "upholding the standards of scientific proof in assessing the impact of leadership practices or organizational arrangements on organizational performance." By reflective, the authors mean "reflection in collaborative management research as the process of jointly creating new insights and theories by referring to the related work of others and the investigation of intervention effects over time." Finally, the authors define relevant research as providing "significant value to the organizations in which it is conducted, as well as provid[ing] opportunities for reapplication of the insights gained to other settings." Pasmore, Woodman, and Simmons review the elements of rigorous, reflective, and relevant research and then offer helpful suggestions to collaborative researchers about how to achieve these ends.

In the next piece, Bradbury (Chapter 28) discusses quality and actionability in action research, which refers to people's ability to use knowledge to produce the actions they want. Bradbury reviews the history of science and points out that the goal of many scientists is to produce knowledge, but not necessarily knowledge that has practical value. Pragmatists started a tradition of 
placing concern with outcomes over concern with method. In action research, the dimensions of quality that affect actionability include practical value, insider/outsider social interaction in defining the research effort, cycles of reflection and action, active experimentation, and representation (how the work is published). Bradbury cites learning histories, which are rich descriptions of the shared inquiry process, as especially helpful in capturing insights and sharing them with others to make a difference.

Coghlan and Shani (Chapter 29) next examine the challenges of collaborative management research communities that confront insiders and outsiders as they endeavor to collaborate. The authors note that there are three distinct activities that deserve special attention by the parties involved in collaborative management research: defining the task, defining the process, and attending to the relationship. Coghlan and Shani argue that the researcher must bring the expertise that can facilitate the design of the collaborative management research community. The designer is challenged to reflect on the many choices that are available and search for the fit among the cultural context, the research content, and the scientific discovery process. Finally, this chapter provides a window into the issues of quality within the collaborative management research community.

The section ends (Chapter 30) with a reflection by the editors of the book on the current state of the art of collaborative management research and some of the challenges it must face as it continues to develop. We also reflect on the insights we have gained from undertaking this effort in the hope that by doing so we create a larger and more tightly knit community of interest in this topic.

\section{CONCLUSION}

Our decision to edit a handbook on collaborative management research was driven by our assessment that this approach is maturing rapidly but possesses no uniform and accepted description, methodologies, or standards that clearly define it. Thus, it is in some scholars' minds currently not differentiated from participative inquiry, collaborative inquiry, action research, or other related communities of interest, which carry out work that may or may not yield knowledge for both the practice and theory of managing complex systems. Our sense at the time was that collaborative management inquiry was beginning to take on a character of its own, and that it was beginning to emerge as a viable strategy to bridge the academic relevancy gap. We felt that establishing a clearer identity for this approach would be important, especially in strengthening opportunities for collaboration with managers who might not be familiar with the approach or its contributions to date. We also thought that it would be important to provide a single compendium of current methods and issues for interested scholars, so that they could more easily build upon what exists in moving ideas forward. We certainly hope that this Handbook adds visibility to the many excellent efforts that have taken place and are under way, and raises issues in the field to a level of discourse in the community that will stimulate its further advance. We don't believe we have succeeded in precisely nailing down the boundaries of the approach, although we have put a stake in the ground asserting that for collaborations, inquiries, and/or research to constitute collaborative management research, there are some minimum standards that should be achieved. We will say more about that in our closing chapter. For now, we hope that we have launched this volume in a way that encourages the reader to take in the full richness of what our contributors have to say, and perhaps inspires a few to join the community of those interested in this important topic. 


\section{REFERENCES}

Adler, N., Shani, A. B. (Rami), \& Styhre, A. (2004). Collaborative research in organizations: Foundations for learning, change, and theoretical development. London: Sage.

Argyris, C. (1980). Inner contradictions of rigorous research. New York: Academic Press.

Argyris, C., Putnam, R., \& Smith, D. (1985). Action science. San Francisco: JosseyBass.

Argyris, C., \& Schön, D. (1982). Theory in practice. San Francisco: Jossey-Bass.

Argyris, C., \& Schön, D. (1989) Participatory action research and action science compared. American Behavioral Scientists, 32, 612-623.

Berger, P., \& Luckmann, P. (1966). The social construction of reality. Garden City, NY: Doubleday.

Bourdieu, P. (1990). The logic of practice. Palo Alto, CA: Stanford University Press.

Brown, L. D. (1990). Participative action research for social change. Human Relations, 46(2), 249-273.

Coghlan, D., \& Brannick, T. (2005). Doing action research in your own organization. Thousand Oaks, CA: Sage.

Evered, R. D., \& Louis, M. R. (1981). Alternative perspectives in the organizational sciences: Inquiry from the inside and inquiry from the outside. Academy of Management Review, 6, 385-395.

Gergen, K. (1982). Toward transformation in social knowledge. New York: Springer-Verlag.

Ghoshal, S. (2005). Bad management theories are destroying good management practices. Academy of Management Learning \& Education, 4, 75-91.

Giddens, A. (1993). New rules of sociological method. Palo Alto, CA: Stanford University Press.

Hoffman, A. (2004). Reconsidering the role of the practical theorist: On (re)connecting theory to practice in organization theory. Strategic Organization, 2, 213-222.

Huff, A. S. (2000). Changes in organizational knowledge production: 1999 presidential address. Academy of Management Review, 25, 288-293.

Kaplan, A. (1964). The conduct of inquiry: Methodology for behavioral science. San Francisco: Chandler.

Kuhn, T. (1962). The structure of scientific revolutions. Chicago: University of Chicago Press.

Lincoln, Y., \& Guba, E. (1985). Naturalistic inquiry. Newbury Park, CA: Sage.

Mitroff, I. (1974). The subjective side of science: A philosophical inquiry into the psychology of the Apollo moon scientists. Amsterdam: Elsevier.

Pfeffer, J., \& Sutton, R. (2006). Hard facts, dangerous half-truths and total nonsense: Profiting from evidence-based management. Cambridge, MA: Harvard University Press.

Reason, P. (1988). Human inquiry in action. London: Sage.

Reason, P., \& Torbert, W. R. (2001). The action turn: Towards a transformational social science. Concepts and Transformation, 6(1), 1-37.

Roethlisberger, F. J., \& Dickson, W. J. (1939). Management and the worker. Cambridge, MA: Harvard University Press. 
Shani, A. B. (Rami), David, A., \& Wilson, C. (2004). Collaborative research: Alternative roadmaps. In N. Adler, A. B. (Rami) Shani, \& A. Styhre (Eds.), Collaborative research in organizations (pp. 83-100). Thousand Oaks, CA: Sage.

Simon, H. (2001). The sciences of the artificial (3rd ed.). Cambridge: MIT Press.

Stymne, B. (2006). The innovative research enterprise. In J. Löwstedt \& T. Stjernberg (Eds.), Producing management knowledge: Research as practice. London: Routledge.

Susman, G. I., \& Evered, R. D. (1978). An assessment of the scientific merit of action research. Administrative Science Quarterly, 23, 583-603.

Tandon, R. (1989). Participatory action research and social transformation. Convergence, 21(2/3), 5-15.

Taylor, F. W. (1911). The principles of scientific management. New York: Harper $\&$ Brothers.

Torbert, W. R. (1976). Creating a community of inquiry: Conflict, collaboration and transformation. London: Wiley.

Torbert, W. R. (1999). The distinctive questions developmental action inquiry asks. Management Learning, 30(2), 189-206.

Trist, E., \& Bamforth, K. (1951). Some social and psychological consequences of the longwall method of coal getting. Human Relations, 1, 3-38.

Weick, K., \& Quinn, R. (1999). Organizational change and development. Annual Review of Psychology, 50, 361-386.

Whyte, W. (1991). Participatory action research. Newbury Park, CA: Sage. 